\title{
Empowering Patients With A Hotline To The Chief Nursing Officer
}

Suzanne J. Crouch, Chamberlain College of Nursing, USA

Karen Ripper, Martin Memorial Health Systems, USA

\begin{abstract}
The purpose of this nursing research study was to explore the perceptions of patients who were provided with a direct line of communication via a "hotline" to the Chief Nursing Officer in order to provide them with a voice in decisions which directly involve their care.

Qualitative analysis revealed recurring themes identifying the "hotline" as reassuring, and offering a level of security. Another theme involved the patients relating situations that needed to be remedied including noise within the hospital environment, waiting for pain medication or using the call light without receiving assistance in a timely manner. Some calls to the hotline centered on compliments for the nursing staff. The findings from this phenomenological study which viewed the hospital world through the lens of patients' eyes have many implications for nursing practice. Implications for nursing practice include enhanced communication among nurses and patients, increased patient satisfaction with their health care experience and improved staff satisfaction in the acute care environment. A hotline to the chief nursing officer is only one way to ensure that the patients'voices are heard and acted upon but this direct line of communication was found to be an effective tool.
\end{abstract}

Keywords: Chief Nursing Officer; Hotline

\section{INTRODUCTION}

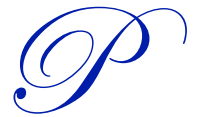

atients who are hospitalized often have a sense of helplessness and loss of control over healthcare decisions that impact their lives (Vitek, 2008). Patients are often silent as nurses and physicians complete walking rounds and state the plan of care in the presence on patients without asking for their input. According to Boykin and Schoenhofer (2001), authentic presence may be understood simply as one's intentionally being there with another in the fullness of one's personhood. Authentic presence may initiate and sustain caring in nursing situations. The nurse must be committed to listening to the voices of patients regarding their values, choices, concerns and requests. Advocacy may be viewed as the moral commitment to foster patients' autonomy (Gadow, 1989). The purpose of this nursing research study was to explore the perceptions of patients who were provided with a direct line of communication via a "hotline" to the Chief Nursing Officer in order to provide them with a voice in decisions which directly involve their care.

\section{Conceptual Framework}

The philosophical framework for this study was based on the Heideggerian interpretive phenomenological method summarized by Brenner (1994). Heidegger reported that by studying a phenomenon "that which shows itself" is revealed "to the things themselves" by the use of ontology, the explanation of Being itself and the revealing of Being entities (Heidegger, M. 1962). This was accomplished by asking the participants during the interview process what it was like to be (during a certain circumstance) and seeking clarification and validation of the story that is told.

\section{Setting}

Two medical surgical floors in two sister medical centers in southeastern Florida served as the setting for this study. The units were a 20 bed inpatient medical/nephrology unit and a 17 bed progressive care/telemetry unit respectively. 


\section{Participants}

A total of 40 patients from two different sister hospitals in southeastern Florida were invited to participate in this qualitative nursing research study over a period of three months. Of the 40 study participants, 30 patients utilized the "hotline".

\section{METHODOLOGY}

Participants met specific inclusion and exclusion criteria in order to participate in the study. Participants were eighteen years of age or older and of any gender and ethnicity. Participants were deemed legally competent and therefore could provide an informed consent. Participants were able to read and speak English. Patients were randomly selected from the daily census reports on the medical/nephrology unit and the progressive care/telemetry unit. The "hotline" number to the Chief Nursing Officer was identified in red on the patient communication board in each of the patient's rooms. The participants were invited to contact the Chief Nursing Officer regarding any aspect of the patient care experience 24 hours per day seven days a week for the duration of the study. On the day of discharge, the patients were contacted by one of the co-investigators for the purpose of conducting a semi-structured interview regarding the patient care experience as it related to the use of the "hotline" to the Chief Nursing Officer.

\section{Instrument}

Questions for semi-structured interviews were as follows:

"Tell me about your experience using the hotline."

"Describe how direct access to the Chief Nursing Officer impacted your patient care experience."

"Is there anything else that you believe may be important for us to know about your experience as a patient?"

\section{DATA ANALYSIS}

The qualitative data from the patient interviews were analyzed using thematic analysis to identify common themes and place them into larger categories (Krueger, 2000). Each of the transcripts was read thoroughly a total of four times by both nurse researchers. The interrater agreement rate between the authors was above $95 \%$. After discussion and refining of the common themes, the agreement between the researchers reached $100 \%$. Qualitative analysis revealed four major themes. The themes that were identified were then compared with field notes in an attempt to confirm consistency between the common themes that were generated from the transcriptions and the summaries of the patient interviews written by the researcher (Morse \& Field, 1995).

\section{The first theme identified the "hotline" as reassuring, and offering a level of security.}

"I felt a comfort that someone in high authority would be available to me. It is nice to know that the owner cares."

"Well, you come in to see me. It's good to know that the hospital cares about what the patient thinks. I have a say so. Something I say might make things better. "I felt I was important enough to have my concerns addressed."

"I really haven't needed to call the hotline at all. In fact, when they reviewed the program with me and indicated what it was all about, I said "well, you guys are so great around here; I'm not so sure I'm going to have to utilize the hotline. But it's a nice comfort to know that it's there."

"I would feel more comfortable in using the hospital. It's nice." 
"I felt that my needs were met and did not need to call you. The charge nurse took care of the one small problem I had with one of the nurses."

"I had a feeling of reassurance knowing I could call the person in charge of the hospital. I never had to, but would have if I was worried about my stay."

"I just think it's a confirmation that if I did have any questions, that people here couldn't answer, I could just pick up the phone and call and that's a nice, comforting feeling."

"It reversed most of my feelings or took what was already a good experience that went negative and reversed it back."

"It was really reassuring to know that if something really needed, I needed someone to talk to about something serious. I think it's serious in the sense that I wouldn't just call up and say "hello, how are you today?", because $24 / 7$, that's pretty heavy duty. It was very comforting because I have been in a situation in a hospital where I really wanted something done and they, just like, ignored me completely. But, here it's been very positive. It makes you feel very secure."

"It felt reassuring to know that I could call about something serious and would not be ignored."

\section{The second theme involved relating a situation that needed to be remedied.}

\section{Pain Medication}

"I called for pain medication but it took forty-five minutes for the nurse to answer the call light."

\section{Sleep Disturbances}

"Lately, they have been waking me up at quarter till 4 to take the blood, do the blood work, and then they would give me one of my shots throughout the day. And, so then I ' $m$ up, and I try to go back to sleep. And, I do, because I can just put my head on the pillow and go back to sleep. Then, they're waking me up at 6 , then 7 , then 8 . No sleep for the weary when you're in the hospital."

Noise

"The only negative factor of my stay that stood out was the noise at night - I wish that people were quieter so I could sleep. Once I got to sleep, it was time for my blood to be drawn again. Everything else was good!"

"But some of them are damn loud; you'd think they're at a bar."

"And they all talk and as they're talking, their voices get louder and louder."

"Well, you know in the middle of the night, those bells start ringing. That's aggravating when I'm sleeping."

"Well, a couple of times in the middle of the night, when they came to do blood work or whatever they do, I want to get back to sleep. They rush out and leave the door open. With all this junk on, I gotta get up and pull this thing around and close the door. And, it's a little aggravating. I don't to bother people and say come and close the door. They're busy. They gotta come and close the door. Just close the door when you leave. It's so easy."

"You have to have the people at night be a little more considerate about the patients that aren't under such medication that they're out all night. I'm not out all night and I hear them laughing. I hear them talking so 
loud, I say please close my door. They don't close my door. It's like I know they were moving and everything. But, just try and be a little more considerate of the people that are in here."

Meals

"The toast for breakfast was awful. That's about the only negative I had. Otherwise, I am a very sick person all the time and need a lot of attention. The nurses gave me very good attention."

"Yes, the food situation. All I could eat was crackers and toast. Every time I got toast, it was burned, so I stopped asking for it."

The third theme revolved around waiting and the hospital schedule.

\section{Waiting}

Waiting was viewed as an important consideration by inpatients in evaluating the quality of the care they received by nurses and hospital personnel.

"My care seems $90 \%$. There were many times I would say, can I have something and I wait a couple hours. With this, as a matter of fact. She pulls the tube out at 6:30 and says someone will be right back; $2 \frac{1}{2}$ hours later somebody came. That's not right. Don't say to me, I'll be will right back. Say, geez it's gonna take me an hour or so. Ok, then I can accept that. But, don't say it's gonna be a few minutes, then 2 hours later, someone comes back."

"Overall, my experience has been pretty good. Except for sometimes I know it takes awhile for them to get to you because there are other patients. But, sometimes I would have to wait like an hour someone just to come. Other nurses were here within minutes."

"Nobody comes. I have waited 45 minutes; I just go in the bed. What are you gonna do?"

"Well, like I had a catheter in and it kept exploding because of what I had done and so they said just take it out, use the bed pan and when you can't get to it, they'll just clean you up. One guy came in and he didn't really know. And, he said well, "if you're gonna have that many trips using the bed pan; you might as well have the Foley put back in." Well, that wasn't the purpose in the first place. The purpose was basically to get me healed down there. He said "if you're on the bed pan too long, it's gonna make a hole right through your skin and that's not a pretty sight." "When he said that I felt just plain stupid."

\section{Hospital Schedule}

"The one thing is that I felt like I almost needed to get a secretary to organize my schedule with all the appointments they had. The doctors were coming in, the nurses were coming in, the therapy was going on. They were taking me to take x-rays or have treatments or whatever it is. So, I guess that's what it's all about. I'm pleased with that because they've taken excellent care. I really do feel comfortable, and I've talked to doctors, friends of mine who live outside of the state and tell them the kind of care I'm getting, and they say I'm getting very good care. I'm telling them every process, because I absorb when the doctors come in and tell me what's going on and the reason I've been in here so long is because my Coumadin levels have not gotten to the level where they need to be. And so, with that, it's a...I'd rather be alive than the alternative."

"Maybe I'm not being fair. It's all different. Everything seems to be rushed. In the room, out of the room. It's hard because when you're sick or on medication, you need the time to think of questions that might pop up. And, if somebody gives you that extra minute of two, you might be able to remember it if you forgot it." 
"I must have all my liquids measured and during the night, they don't empty my hat often enough so that I can go."

"I called the hotline because I wanted to send a copy of my medical record to my family doctor back home. I am not from here and I would like his input in making decisions about my care. Can you help me cut through the red tape to get this done quickly?"

\section{The fourth theme centered on compliments for the nursing staff.}

"I have been a patient in many hospitals, but the nurses in this hospital are the best I have ever encountered."

"She's a pistol. She's funny. I can't believe she's from the Midwest somewhere. She's has a New York attitude, like I kind of did. I said, oh-oh, we're gonna butt heads. She was fine. You sound just my girlfriend yelling at me. She said I wasn't yelling at you. I was just trying to get your attention. You were in the bathroom; I didn't know if you could hear me. So, I started yelling for you. So, we kind of laughed about that. But, as the days worn on, she was very attentive and everything. Even when she worked the other end of the floor, she took the time to come down and see me. See how I was feeling. And, I had questions about certain tests that scared me a little bit. She explained them to me. Took the time to print out something so I felt comfortable with the procedure. She's so nice."

"Service was excellent - food, nurses, housekeeping - the BEST. My sister, from New York, when visiting, wouldn't believe how clean the facilities were."

"They've done everything they can for me."

"Everybody here was so wonderful. Every nurse I had; every PCT I had made it all like family."

\section{Hospital Staff}

The lived experience of the hospitalized patient illustrated a connectedness between the patient and hospital workers, other than nurses, in the hospital environment. Consistently, patients described their experiences with ancillary staff such as housekeeping, dietary and laboratory personnel.

"This is about the person who cleans. She's so sweet. And, we talk when she was cleaning the room. Little things like that make you feel comfortable; when people take the time."

"There was a lady from the kitchen and we have kind of been hitting it off. She said one time we'll get together or something. I don't know if it's OK for her to do that. But, when she brings the meals up, she brought me a magazine."

“The switchboard operator....I can't remember her name. She sent me a book the first weekend I'm here. Something to laugh about. I get along with people easy. But, usually when you're in the hospital, everybody's so cut and dry."

"I am calling to let you know that the nurses in this hospital are just the best."

\section{Reasons why patients did not call the hotline}

"I felt that my needs were met and did not need to call you. The charge nurse took care of the one small problem I had with one of the nurses." 
"It's been fabulous. I love the nurses and you know, the practitioners. I call them that. They call them techs. They've been really, really good to me. They're always asking if they can do more. It's been a very positive experience. And, I've been here a long time.

“Actually, I was gonna call you yesterday. I had a nurse yesterday; I don't remember what her name is. She was a dayshift nurse. She doesn't normally work this floor. But, she came in and gave me an attitude and was really ignorant towards me, because I told her the way they had been giving me my medication here and she tried to tell me that I was wrong. That I don't get stuff that way. So, I had her go get the charge nurse. She come in, and took care of the problem. I could say $90 \%$ of the nurses did a wonderful job."

“Well, I had a bad experience Sunday night. My roommate was loud and I just didn't get any sleep. So, the nurse came in on Monday morning and I don't know, maybe it was around 10:00. I said to her, ya know, I gotta have a different room. And, she said she knew about this room. And, she said I think it's available. But, she said "I'm gonna have to wait" and so she came in about 1:00 and said "we got it." And, we walked right over here. That makes me feel good."

"Well on a comparative basis I won't mention where, but I went to another hospital and the doctors and nurses, they were not really concerned with what was really wrong with me. I felt neglected. Here, I certainly didn't feel neglected. The doctors visit, I can't believe how often and caring they came across. And, the nurses are, as I said, wonderful. I guess I don't know if I should compare because there is so many hospitals, but here I felt it was the best situation. I would highly recommend the hospital to anybody else if they had to come for something."

\section{DISCUSSION}

The findings from this phenomenological study viewing the hospital world through the lens of patients' eyes have many implications for nursing practice. Implications for nursing practice include enhanced communication among nurses and patients, increased patient satisfaction with their health care experience and improved staff satisfaction in the acute care environment. Additionally, potential benefits to participants may include a better understanding of nursing practices grounded in authentic presence. Furthermore, nursing has a moral responsibility to speak with patients' voices (Gadow, 1989). Speaking with patients' voices is a professional responsibility that becomes the catalyst for expanding the body of nursing knowledge as it relates to discovering methods to better care for patients. The chief nurse often is distracted by the business side of the organization with budget meetings, strategic planning and community affairs and is drawn away from the direct needs of the patients. By engaging in a hotline as a direct means of communication with the patients, the chief nurse may stay in touch with the heart of the business which is the patients. Direct patient interaction through a hotline to the chief nursing officer was the incentive for an initiative to adopt hourly rounding and bedside shift reports. If we, as nurses, believe that patients have a right to be active participants in their health-care experiences, then we must give voice to their values, choices, concerns and requests.

\section{Limitations of the Study}

The study used a convenience sample and therefore cannot be generalized to the population at large. It is anticipated that this preliminary study will form the basis for more research on this topic and therefore replication of the study is suggested. Another limitation to the study was the fact that the hotline number to the chief nursing officers was written on the patient communication board. In actuality, the staff could then become aware of which patients were included in the study and preferential treatment could have resulted leading toward a basis for biases in the study.

\section{Implications for Nursing Practice}

The purpose of this nursing research study was to explore the perceptions of patients who were provided with a direct line of communication via a "hotline" to the Chief Nursing Officer in order to provide them with a voice in decisions which directly involve their care. While reaching the chief nursing officer through a hotline is a tool that can be used by patients to ensure that their voices are heard and acted upon, another purpose for a hotline might be 
for direct contact with the director of each of the units. Since the usual method of responding to the patients requests or concerns involved notification of the director of each of the respective units, it might be feasible for each of the directors to carry a cell phone for the specific reason of direct patient communication. In this manner, the director would not be a position that the patient was "going over their head" to reach a remedy to the situation that precipitated the call. A hotline to the chief nursing officer is only one way to ensure that patients' voices are heard and acted upon but this direct line of communication was found to be an effective tool.

\section{AUTHOR BIOGRAPHIES}

Dr. Suzanne Crouch, Ed.D., MSN, ARNP, RN-BC, CNE, has been a nurse educator for over twenty-five years and presently is a Professor of Nursing at Chamberlain College of Nursing. Email: suzannecrouch@aol.com

Ms. Karen Ripper, RN, CNAA, FACHE, has more than thirty years of experience in nursing leadership. Formerly, Ms. Ripper was the Chief Nursing Officer and Senior Vice President of Martin Memorial Health Systems. Presently, Ms. Ripper is the President and CEO of the Charles and Rae Kane Center, Council on Aging of Martin County, Inc. in Stuart, FL. Email: kripper@kanecenter.org

\section{REFERENCES}

American Nurses Association Bill of Rights for Registered Nurses, (2001), ANA website: http://nursing world.org/.

Annells, M. (2007) What's common with qualitative nursing research these days? Journal of Clinical Nursing, 16(2), $223-224$.

Bennis, W., \& Townsend, R., (2005). Reinventing leadership: Strategies to empower organizations. Collins Business Publishers. New York, NY.

Boykin, A. \& Schoenhofer, S. (1993). Nursing as caring: A model for transforming nursing practice. National League for Nursing Press. Boston: Jones and Bartlett.

Brenner, P. (1994). The tradition and skill of interpretive phenomenology in studying health, illness, and caring practices. In: Brenner, P. ed. Interpretive Phenomenology: Embodiment, Caring and Ethics in Health and Illness. Thousand Oaks, CA: Sage; 1994:99-127.

Byrne, M. (2001) Hermeneutics as a methodology for textual analysis. AORN, 73( 5), 968-970.

Covey, S. (2004). 7 Habits of highly effective people. Free Press. New York, NY.

Crist, J.D., Tanner, A. (2003) Interpretation/analysis in hermeneutic interpretive phenomenology. Nursing Research, 52( 3), 202-205.

Crotty, M. (1996) Phenomenology and Nursing Research. South Melbourne: Churchill Livingstone.

Dowling, M. (2004) Hermeneutics: an exploration. Nurse Researcher, 11(4), 30-41.

Drauker, C.B. (1999) The critique of Heideggerian hermeneutic research. Journal of Advanced Nursing, 30, 36-73.

Gadow, S. (1989). Clinical subjectivity: Advocacy with silent patients. Nursing Clinics of North America, 24(2), 535-541.

Green, J., Thorogood, N. (2004) Qualitative Methods for Health Research. London: Sage Publications.

Hank, R. (2008,). The lived experience of nursing advocacy. Nursing Ethics, 15(4), 468-477.

Heidegger, M. (1962) Being and Time. New York, NY: Harper and Row.

Husserl, E. (1963) Ideas: a General Introduction to Pure Phenomenology. Translated by Boyce

Gibson, W.R. New York, NY: Collier Books. From the German original of 1913.

Johansson, P., Oleni, M., \& Fridlund, B. (2001, April). Patient satisfaction with nursing care in the context of health care: A literature study. Scandinavian Journal of Caring Sciences, 16(4), 337-344. Retrieved November 7, 2008, from Inter Science database.

Koch, T. (1995) Interpretive approaches in nursing research: the influence of Husserl and Heidegger. Journal of Advanced Nursing 21(5), 827-836.

Kohn, L., Corrigan, J. \& Donaldson, M., eds. (2000). To err is human: Building a safer health system. Washington, DC: National Academy Press.

Koloroutis, M. ed. (2004) Relationship-based care: A model for transforming practice. Creative Health Care Management, Minneapolis, MN.

Krueger, R. A. (2000). Focus groups: A practical guide for applied research. Thousand Oaks, CA: Sage.

Jasper, M. (1994) Issues in phenomenology for researchers of nursing. Journal of Advanced Nursing, 19, 309-314.

Leninger, M. M. (1981). Caring: An essential human need. Charles B. Slack. Thofare, NJ

Lein, C., \& Willis, C. (2007, May). Using patient-centered interviewing skills to manage complex patient encounters in primary care. Journal of the American Academy of Nurse Practitioners, 19(5), 215-220. Retrieved January 11, 2009 from CINAHL Plus with Full Text database.

Lopez, K., Willis, D. (2004) Descriptive versus interpretive phenomenology: their contributions to nursing knowledge. Qualitative Health Research, 14(5), 726-735. 
Manthey, M (2003). Aka Primary Nursing, Journal of Nursing Administration, 33, 7/8, p 369-370. Nursing: Scope and Standards of Practice, (2004) American Nurses Association, Silver Spring, MD.

Mayeroff, M. (1971). On caring. Harper Perennial. New York, NY.

Morse, J., \& Field, A. (1995). Qualitative methods for health professionals. Thousand Oaks, CA: Sage.

Oiler, C. (1982) The phenomenological approach to nursing research. Nursing Research, 31(3), 178-181.

Parahoo, K. (2006) Nursing Research: Principles, Process and Issues. Hampshire: Palgrave Macmillan.

Peters, R. J. \& Waterman, R. H. (1982). In search of excellence. Harper \& Row. New York, NY.

Pipe, T., Conner, K., Dansky, K., Schraeder, C., \& Caruso, E. (2005, November). Perceived involvement in decision-making as a predictor of decision satisfaction in older adults. Southern Online Journal of Nursing Research, 6(4), 1-13. Retrieved January 11, 2009, from CINAHL Plus with Full Text database.

Redman, R., \& Lynn, M. (2005, September). Assessment of patients' expectations for care. Research \& Theory for Nursing Practice, 19(3), 275-285. Retrieved January 11, 2009, from CINAHL Plus with Full Text database.

Roach, S. (1984) Caring: The human mode of being, implications for nursing. University of Toronto. Toronto, Canada.

Robinson, J., Callister, L., Berry, J., \& Dearing, K. (2008, December). Patient-centered care and adherence: Definitions and applications to improve outcomes. Journal of the American Academy of Nurse Practitioners, 20(12), 600-607. Retrieved January 11, 2009, from CINAHL Plus with Full Text database.

Sandelowski, M. (1995) Qualitative research: what it is and how to begin. Research in Nursing and Health, 18, 371-375.

Sandelowski, M. (1994) The use of quotes in qualitative research. Research in Nursing and Health, 17, 479-82.

Sidani, S., Epstein, D., \& Miranda, J. (2006, September). Eliciting patient treatment preferences: A strategy to integrate evidencebased and patient-centered care. Worldviews on Evidence-Based Nursing, 3(3), 116-123. Retrieved January 11, 2009, from CINAHL Plus with Full Text database.

Streubert-Speziale, H.J., Carpenter, D.R. (2003) Qualitative Research in Nursing: Advancing the Human Imperative. London: Lippincott Williams and Wilkins.

Vitek, L., \& Rosenzweig, M. (2007). Distress in patients with cancer: Definition, assessment, and suggested interventions. Clinical Journal of Oncology Nursing, 11(3), 413-418.

Watson, J. (1979). Nursing: The philosophy and science of caring. Little Brown, Boston, MA Reprinted/republished 1985. Colorado Associated University Press. Boulder, CO.

Watson, J. (2008). Nursing: The philosophy and science of caring. University Press of Colorado, Boulder, CO.

Wimpenny, P., Gass, G. (2000) Interviewing in phenomenology and grounded theory: is there a difference? Journal of Advanced Nursing, 31(6), 1485-1492. 